\title{
Development and Evaluation of Korean Nurses' Core Competency Scale (KNCCS)
}

\author{
Won-Hee Lee', Sanghee Kim${ }^{2 *}$, Jihyoun $\mathrm{An}^{3}$ \\ ${ }^{1}$ College of Nursing, Yonsei University, Seoul, South Korea \\ ${ }^{2}$ College of Nursing \& Mo-Im Kim Nursing Research Institute, Yonsei University, Seoul, South Korea \\ ${ }^{3}$ Severance Hospital, Yonsei University Health System, Seoul, Korea \\ Email: *sangheekim@yuhs.ac
}

How to cite this paper: Lee, W.-H., Kim, S. and An, J. (2017) Development and Evaluation of Korean Nurses' Core Competency Scale (KNCCS). Open Journal of Nursing, 7, 599-613.

https://doi.org/10.4236/ojn.2017.75045

Received: March 20, 2017

Accepted: May 23, 2017

Published: May 26, 2017

Copyright $\odot 2017$ by authors and Scientific Research Publishing Inc. This work is licensed under the Creative Commons Attribution International License (CC BY 4.0).

http://creativecommons.org/licenses/by/4.0/

\begin{abstract}
Purpose: The purpose of this study was to develop and evaluate a Korean Nurses' Core Competency Scale (KNCCS). Methods: This methodological research was conducted over two major steps. The first step involved developing a preliminary 70-item KNCCS based on an extensive literature review and the standards and criteria proposed by the Korean Accreditation of Nursing. The second step involved evaluating validity and reliability of the KNCCS. 528 newly graduated nurses recently employed in nine major hospitals were participated in this research for validation. Results: The final KNCCS consisted of 70 items. The exploratory factor analysis identified five subscales under which each item could be categorized: 1) human understanding and communication skills; 2) professional attitudes; 3) critical thinking and evaluation; 4) general clinical performance; and 5) specific clinical performance. Conclusion: The KNCCS shows good reliability and validity. However, the test of both criterion and construct validity were recommended further.
\end{abstract}

\section{Keywords}

Competency, Scale, Nursing Education, Korea

\section{Introduction}

Nurses compose over a third of the workforce in hospitals, providing clinical and nursing care around the clock often in a collaborative multidisciplinary approach [1] [2]. The competence of nursing students is related to the quality of nursing care they provide, their cooperation with individuals from other disciplines and services, and, ultimately, patient health and safety. Inasmuch the professional standards of nurses rely on their competency, evaluating nurses' competence is an important and fundamental issue in healthcare.

Nursing education programs provide the education and training needed to 
foster strong core competencies in nursing students. The vast amount of literature on measuring nursing core competency and factors related to it indicates how importance of such performance indicators for health professionals. This is unsurprising because the core competency of nurses is a measure of their ability to carry out nursing tasks at a professional level. Core competency is known to be influenced by various factors such as clinical environment, knowledge, technical skills, decision-making skills, and abilities of a nurse [3]. In nursing education, it is defined as the performance level a candidate must demonstrate to graduate from the baccalaureate nursing education program. The assessment of the core competencies of graduating nurses has been based on variables such as education goals and the curricula of baccalaureate nursing education programs [4] [5].

Notwithstanding this, the assessment of nurses' core competency, as shown in the Korean literature, has been performed without an agreement on competence domains among researchers, leading to difficulties in generalization and applicability of findings [6]. This has also resulted in inconsistencies in terminology and their definitions. For instance, terms such as nursing core competence [7], professional nursing competence [8], and clinical competency [9] [10] [11] have been used interchangeably without clear grounds to do so. In addition, most scales that assess nursing core competency lack a clear conceptual framework or have applied those of foreign scales without making the necessary adaptations to the educational context specific to Korea. Thus, there is a clear need for a standardized rigorously validated core competency scale that accurately assesses how well equipped are graduating baccalaureate nurses in the Korean context.

To this end, we developed a scale that quantitatively measures the core competencies of Korean nurses on the basis of an extensive literature review of preexisting tools by a pilot test of a preliminary competency scale. A validation of the KNCCS was carried out in this actual study to assess its reliability and validity.

\section{Methods}

\section{Study design}

This study was designed with methodological study for developing and evaluating the instrument to measure nurses' core competencies of nurses in Korea.

\section{Participants}

The total population of the pilot study comprised 615 graduating baccalaureate nurses. They were recently hired employees at nine Seoul-or Gyeonggibased secondary hospitals and tertiary hospitals and were awaiting practical orientation at their new employment. Of the 615 nurses, 528 nurses who agreed to the aims of the study and gave their informed consent volunteered. The 70item self-assessed questionnaires were distributed to the nurses at the hospital and retrieved through a deposit box. The response rate was $85.8 \%$ and the subject per item ratio was 7.5, well met for general rule of scale development of 5 to 10 subject per item ratio. 


\section{The instrument}

We developed a preliminary scale composed of a self-assessed questionnaire on general characteristics and core competencies. This preliminary KNCCS was based on core and clinical competence scales developed in other countries. Content validity of the preliminary scale was assessed by a content expert panel consisting of nursing professors and of educators from health care institutions who coach novice nurses. The 70 item-preliminary scale was constructed into 5 sub-domains or subscales (critical thinking, clinical performance, communication skills, human understanding, and professionalism and ethics) (Table 1), and each item was rated using a 5-point scale with the following rating continuum $(1=$ strongly disagree, $2=$ disagree, $3=$ neutral; $4=$ agree, and $5=$ strongly agree). We developed seven binary or multiple-choice items pertaining to general characteristics: specifically, age, sex, religion, and the type of nursing education programs and three items on a 5-point scale on self-efficacy including self-appraisals of their performance during the baccalaureate program; self-appraisals of their nursing competence during clinical training; and the level of confidence in their own competence.

\section{Data collection and analysis}

For the data collection, we recruited participants from nine nursing departments of either secondary or tertiary major hospitals in Seoul or Gyeonggi region. Recently graduated nurses who approved the study rationale and volunteered to participate were recruited. By choosing the hospitals that employ nurses without regional discrimination, we were able to eliminate any geographical bias in the participant selection process. We explained the rationale of the study and the overall plan to the nursing managers of the hospitals and received their approval for participant recruitment, after which the same explanation was given to newly graduated nurses awaiting their practical orientation at the hospital. We distributed our preliminary KNCCS to the participants who after self-assessment, sealed the questionnaire into an envelope themselves and placed it into a deposit box anonymously. The collected responses were codified and statistically analyzed. The explanatory factor analysis was performed using SPSS program.

\section{Ethical considerations}

The study was approved by the college's Institutional Review Board (IRB

Table 1. Proposed preliminary Korean nurses' core competency scale.

\begin{tabular}{|c|c|c|c|c|c|}
\hline Sub scales & 1 & 2 & 3 & 4 & 5 \\
\hline $\begin{array}{l}\text { Labeled } \\
\text { name }\end{array}$ & Critical thinking & $\begin{array}{c}\text { Clinical } \\
\text { performance }\end{array}$ & $\begin{array}{c}\text { Communication } \\
\text { skills }\end{array}$ & $\begin{array}{c}\text { Human } \\
\text { understanding }\end{array}$ & $\begin{array}{l}\text { Professionalism } \\
\text { \& ethics }\end{array}$ \\
\hline $\begin{array}{l}\text { Number } \\
\text { of items }\end{array}$ & 12 & 21 & 13 & 10 & 14 \\
\hline $\begin{array}{c}\text { Item } \\
\text { example }\end{array}$ & $\begin{array}{l}\text { Based on nursing assessment, } \\
\text { I can do nursing diagnosis } \\
\text { and choose the } \\
\text { best intervention }\end{array}$ & $\begin{array}{c}\text { I can carry out } \\
\text { appropriate nursing } \\
\text { assessment skill } \\
\text { including history taking } \\
\text { and physical examination }\end{array}$ & $\begin{array}{l}\text { I can perform } \\
\text { therapeutic } \\
\text { communication } \\
\text { skill }\end{array}$ & $\begin{array}{l}\text { I can understand } \\
\text { my patient who } \\
\text { has spirituality }\end{array}$ & $\begin{array}{l}\text { With recognition of } \\
\text { my institutional } \\
\text { philosophy and policy, } \\
\text { I can follow it as a } \\
\text { health professional }\end{array}$ \\
\hline
\end{tabular}


2009-0018). We ensured that the participant recruitment process permitted only those who gave their informed consent. Data collection and data analysis were conducted in a way that guaranteed protection of sensitive, personally identifiable data and anonymity of participants. And the following instructions were adhered to: 1) the patients' informed consent forms were collected separately from the questionnaires; 2) the self-assessed questionnaires were sealed and placed in a deposit box by the participants themselves. Additionally, although the nurses had not even begun the hospital practical orientation at the time of self-assessment, we still made clear that participants declared any potential conflicts of interest between them and the institutions; and lastly; 3) the questionnaires and its parts were handled as unique codes for analysis purposes.

\section{Results}

\section{Developing the KNCCS}

\section{1) Development of the KNCCS}

We developed a preliminary scale to assess Korean nurses' core competency. This pilot instrument in the form of a questionnaire was structured into a 5domain framework as an outcome of an extensive literature review. The items in the scale were created following the frameworks already outlined in nursing core competence scales developed elsewhere.

Our questionnaire comprised five main competence domains: 1) Critical thinking; 2) Clinical performance; 3) Communication skills; 4) Human understanding; and 5) Professionalism and ethics.

We defined Critical thinking as the process of problem-solving and decision-making, drawing upon various cognitive skills as the process requires, such as analyzing, evaluating, and collecting; inference, inductive, and deductive reasoning; prioritizing; and applying knowledge. Items used to measure this domain covered ideas of problem perception, evidence-based nursing practice, prioritizing issues, applying standards to multiple complex principles, clinical decision-making, and holistic nursing. We defined Clinical performance to constitute clinical application of the nursing process (including patient data collection), basic nursing skills, and teaching and supervising. Items on patient assessment, application of the nursing process, technical and clinical skills, use of medical equipment, documentation and information technology, clinical intervention, understanding and applying complementary alternative medicine, emergency and critical care, nursing of dying patients, nursing education, and transitional care were used to measure this domain. Communication skills refer to the ability to communicate with patients and their families, with colleagues, with nursing students, and with interdisciplinary teams. The items used to measure this domain included content on communication and on modes of communication. We defined Human understanding as the ability to make a differentiated approach to interpersonal relationships by being aware of the distinct needs of colleagues, patients, and families. The items used to measure this domain assessed, for example, a nurse's ability to discriminate the physical, mental, 
social, and spiritual needs of patients and, hence, to provide differential nursing based on this needs assessment. Professionalism and ethics refers to the conduct of good nursing practice following legal and ethical principles, to continual professional development, to the provision of the highest standard of nursing care through collaboration, social participation, and quality improvement. Specifically, items measuring professionalism covered topics on ethical nursing practice; professional development; and professional attitudes. Those measuring accountability covered areas of delegation and personal and professional development. Specific examples of items in each domain are shown in Table 1.

\section{2) Validity of the scale using the content validity index}

The content validity of the scale was confirmed using the method devised by Polit \& Beck [12]. We measured the content validity index of the overall scale (S-CVI), the proportion of items on a scale that achieves a relevance rating of 3 or 4 by all content experts (S-CVI/UA), the average of the I-CVIs for all items on the scale (Scale-CVI/Ave), and the content validity index of individual items (I-CVI) [12]. The seven expert panels who evaluated the relevance of each item in the scale were nursing professors with at least 20 years' experience in nursing education. The scale's content was rated in terms of its relevance to the construct being measured with a questionnaire developed by Lynn (1986). Each item was rated on a 4-point scale to avoid having an ambivalent midpoint $(1=$ not relevant, $2=$ somewhat relevant, $3=$ quite relevant, $4=$ highly relevant $)$, and the individual I-CVI ratio was computed as the number of 3 or 4 ratings, thus dichotomizing the scale into either relevant or not relevant [13].

The content validity analysis of the KNCCS revealed only 30 items whose content was judged as being relevant by seven expert panels unanimously, scoring an S-CVI/UA of 0.43 . The S-CVI/Ave was 0.86 , and the range of the I-CVI was $0.14-1.0$. Our validity testing also showed that seven items had an I-CVI of less than 0.7 (item 17; item 24; item 26; item 38; item 54; item 55; and item 56).

\section{Validating the KNCCS}

\section{1) General characteristics of respondents}

The participants for the pilot testing of KNCCS included 528 graduating nurses. The majority of participants were women (95.5\%), and the mean age of the graduating nursing students was $24.6 \pm 1.7$ years (range, $22-33$ years). The majority of participants were either Christians or Catholics (53.6\%). We found that $75 \%$ of respondents were baccalaureate graduates from either a traditional BSN program or a RN-BSN program. On a rating continuum from 1 to 5 ( $1=$ least competent, $5=$ most competent), the participants self-appraised their performance during the baccalaureate program as $3.68 \pm 0.66$; their nursing competence as $3.73 \pm 0.66$; and their level of confidence as $3.78 \pm 0.73$ (Table 2).

\section{2) Reliability}

The reliability of the KNCCS was assessed through an item analysis in terms of initial reliability and test-retest reliability. The item analysis revealed that none of the items showed an item-total correlation of less than 0.3 and that the item-total correlation ranged between 0.470 and 0.700 for all items. When we 
Table 2. General characteristics of respondents.

\begin{tabular}{|c|c|c|}
\hline & \multirow{2}{*}{ Frequency (Valid percent) } & $(N=528)$ \\
\hline & & Mean \pm SD (Range) \\
\hline \multicolumn{3}{|l|}{ Gender } \\
\hline Female & $504(95.5 \%)$ & \\
\hline Male & $24(4.5 \%)$ & \\
\hline Age (yr) & & $24.6 \pm 1.7(22-33)$ \\
\hline \multicolumn{3}{|l|}{ Religious affiliation } \\
\hline Protestantism & $201(38.1 \%)$ & \\
\hline Catholicism & $82(15.5 \%)$ & \\
\hline Buddhism & $30(5.7 \%)$ & \\
\hline None & $214(40.5 \%)$ & \\
\hline Other & $1(0.2 \%)$ & \\
\hline \multicolumn{3}{|l|}{ Educational background } \\
\hline 3-year community college & $126(23.9 \%)$ & \\
\hline Traditional BSN & $385(72.9 \%)$ & \\
\hline RN-BSN & $11(2.1 \%)$ & \\
\hline Double Major/Others & $6(1.1 \%)$ & \\
\hline Self-recognized accomplishment & & $3.68 \pm 0.66(1-5)$ \\
\hline Self-evaluated nursing practice & & $3.73 \pm 0.66(2-5)$ \\
\hline Self-efficacy & & $3.78 \pm 0.73(1-5)$ \\
\hline
\end{tabular}

computed the initial reliability, we found that our preliminary KNCCS showed a Cronbach's alpha coefficient of 0.97 . To check the consistency of results, 42 nurses from one hospital ( $8 \%$ of the study population) were asked to repeat the questionnaire. The retesting was performed within a period of 10 days of the first testing (still before their practical orientation, to calculate the test-retest reliability; the resulting correlation coefficient was 0.84 (Confidence Interval = 0.65 to $0.93, p<0.001$ ) (Table 3 ). All statistical analyses were performed using SPSS 18.0

\section{3) Exploratory factor analysis}

We used explanatory factor analysis to determine the factor structure of the responses of our 70-item preliminary scale. To do this, we performed a principal component analysis with Varimax rotation and Kiser Normalization. We found that the Kaiser-Meyer-Olkin (KMO) measure of sampling adequacy was 0.97 (marvelous) and that the Bartlett's test of sphericity was 0.000, thereby, demonstrating the suitability of our data for factor analysis.

Our analysis revealed 12 factors with an Eigenvalue of greater than 1.0 and found they explained $61.76 \%$ of the variance in the scale. Since the preliminary study was founded on five core competence domains, we computed the Eigenvalue again, but using only five domains this round, and found an Eigenvalue 
Table 3. The finalized Korean nurses' core competency scale.

\begin{tabular}{|c|c|c|c|c|c|}
\hline Title & \multicolumn{5}{|c|}{ Korean Nurses' Core Competency Scale (KNCCS) } \\
\hline $\begin{array}{c}\text { Detailed } \\
\text { description }\end{array}$ & \multicolumn{5}{|c|}{$\begin{aligned} 70 \text { items, } 5 \text { subscales } & \\
\text { 49.94\% of variances explained, Cronbach's alpha } & =0.97 \\
\text { Test-retest reliability alpha }=0.84, \text { Item total correlation } & =0.047-0.70\end{aligned}$} \\
\hline Subscales & 1 & 2 & 3 & 4 & 5 \\
\hline $\begin{array}{l}\text { Labeled } \\
\text { names }\end{array}$ & $\begin{array}{l}\text { Human } \\
\text { understanding } \\
\text { \& Communication } \\
\text { skills }\end{array}$ & $\begin{array}{c}\text { Professional } \\
\text { Attitudes }\end{array}$ & $\begin{array}{l}\text { Critical } \\
\text { thinking } \\
\text { and Evaluation }\end{array}$ & $\begin{array}{c}\text { General } \\
\text { Clinical } \\
\text { Performance }\end{array}$ & $\begin{array}{c}\text { Specific } \\
\text { Clinical } \\
\text { Performance }\end{array}$ \\
\hline $\begin{array}{l}\text { Number } \\
\text { of items }\end{array}$ & 21 & 13 & 14 & 13 & 9 \\
\hline $\begin{array}{l}\text { \% Variance } \\
\text { explained }\end{array}$ & $12.6 \%$ & $11.2 \%$ & $10.4 \%$ & $8.6 \%$ & $7.2 \%$ \\
\hline $\begin{array}{c}\text { Cronbach's } \\
\text { alpha coefficient }\end{array}$ & 0.94 & 0.92 & 0.90 & 0.91 & 0.84 \\
\hline Factor loadings & $0.35-0.66$ & $0.44-0.73$ & $0.43-0.66$ & $0.34-0.69$ & $0.08-0.61$ \\
\hline
\end{tabular}

greater than 5.1. We found that the five domains explained $49.94 \%$ of the variance. The sub-domains derived from the factor analysis were named as Human understanding and communication skills, Professional attitudes, Critical thinking and evaluation; General clinical performance, and Specific clinical performance. And after the validation of the scale through reliability and validity testing of items and of subscales, we were able to develop the final scale (Table 3 ).

The results of the analysis show that 69 items had a factor loading of more than 0.03 in at least one factor. Only one item (item 29) had a factor loading of less than 0.3 , which had a factor loading of 0.08 (Table 3).

\section{4) The final KNCCS}

On the basis of the reliability and validity testing, we finalized the KNCCS that would be used to measure the core competency of recently registered baccalaureate nurses in Korea. Of note, we agreed not to omit the subscale concerning 'spiritual care', although it was associated with a factor loading of less than 0.3 , because we considered it an integral part of good nursing practice. Thus, the final KNCCS contains 70 items structured in 5 subscales; Human understanding and communication skills (21 items); Professional attitudes (13 items); Critical thinking and evaluation (14 items); General clinical performance (13 items); and Specific clinical performance (9 items) (Appendix 1).

\section{Discussion}

In this methodological study, we developed the KNCCS and evaluated its reliability and validity. Here, we discuss why it is important to measure core competencies of Korean nurses, appraise the content of the selected items, and, on the basis of this appraisal, evaluate the appropriateness of the scale in measuring core competency.

\section{Rationale for measuring Korean nurses' core competency}

In 2008, Axley explored the multidimensional aspects of competency and 
considered the following concepts integral to the definition of nursing competency: 1) knowledge derived from information, education, and training; 2) actions in ability, patterns, procedures, and techniques; 3) professional standards; 4) organizational policies affecting responsibility, attitudes, autonomy, motives, and self-regulation; and 5) dynamics such as societal change and constant quality improvement [14].

A pre-requisite to acquiring these competencies relies heavily on receiving education and all ancillary skills that come with receiving an education. Specifically, this means that nurses must 1) earn the relevant nursing education degrees; 2) have clear standards of their activities and actions; and 3) show accountability, all of which should in line with the knowledge that they have attained through the nursing education program. Evidence of having achieved the level of core competency expected in nurses includes improved safety of patients, provision of patient care of the utmost standard, application of key knowledge, and self-driven professional development through continuing education [14]. Graduating nurses should be equipped with the appropriate core competency by the time they graduate so that the outcomes of their cultivated skills are directed to the right end-consumer, which is the patient. For these reasons, there is a need to assess the core competency of Korean nurses and develop tools to do so.

\section{Composition of the KNCCS}

We reviewed literature and compared the frameworks of preexisting competency scales so that we could analyze the trends and composition of core competencies of nurses. With the advent of the Six-Dimension Scale of Nursing Performance Scale (Six-D Scale) [15], a plethora of similar scales with subscales adapted in accordance to the specific needs and context of each country was developed. The Six-D Scale contains 52 items grouped into six subscales on leadership, critical care, teaching/collaboration, planning/evaluation, interpersonal relations/communications, and professional development. A study validated the Six-D Scale on 914 newly registered US nurses and 587 supervisors and reported it as a highly reliable performance evaluation instrument. This scale has been adapted and translated into Korean and tested on nursing students and registered nurses in Korea to evaluate their clinical performance [8] [10].

The Finnish Nurse Competence Scale (NCS) contains 73 items rated on a 4point scale. It has been validated on 498 Finnish nurses. The conceptual framework of NCS was derived from Benner's From Novice to Expert competency framework [16]. Subscales include responsibilities of the collaborator, teaching and diagnostic function, situational management, treatment interventions, maintaining quality care, and accountability [17].

The Self-Evaluated Core Competencies (SECC) Scale is a 4-point scale developed by the Taiwan Nursing Accreditation Council. Eight core competencies established in the scale are critical thinking, general clinical nursing skills, basic biomedical science, communication and cooperation, caring spirit, ethics, accountability, and lifelong learning. A principal components analysis of the scale 
identified two components of core competencies, namely humanity/responsibility and cognitive/performance. And the scale was validated using the responses of 802 nursing students pending graduation [5].

The Australian National Competency Standard Inventory (ANCI) national competency standards for enrolled nurses were developed by the Australian Nursing Council. The 51-item ANCI national competency standards are structured into 14 elements covering four domain competencies: professional practice, critical thinking and analysis, management of care, and enabling. Further, the self-assessed levels of competence (of 116 Australian nurses) derived from the ANCI national competency standards were shown to have a statistically significant relationship with those derived from the NCS $(r=0.75)$ [18], demonstrating convergent validity of ANCI.

The Competency Inventory for Registered Nurses (CIRN) for Chinese registered nurses is a scale based on the ICN Framework of Competencies for the Generalist Nurses developed by the International Council of Nurses (ICN), which categorizes nursing competencies into three domains: Professional, ethical, and legal practice; Care provision and management; and Professional, personal, and quality development. The CIRN scale contains 58 items rated on a 5-point Likert scale. Through a validation study on 533 registered nurses in Macao, the overall CIRN scale was found to have an internal consistency of a Cronbach's alpha of 0.908 . Their confirmatory factor analysis indicated a 7-factor structure for this scale with 55 items, where three items with low factor loading were eliminated. The seven subscales were clinical nursing, leadership, interpersonal skills, legal and ethical responsibilities, professional development, education and coaching, and critical thinking and research attitudes [19].

Ideally, the core competency of nurses should be acquired through a formal baccalaureate program in nursing. And the standards identified by international nursing councils or associations should form the basis of the conceptual framework of core competency scales. Conceptualizing and integrating competencies such as critical thinking, professional attitudes and ethics, interpersonal skills, and communication skills are important to make scales as context-relevant as possible. In other words, the scale must be a reflection of not only the Korean nursing education and assessment system but also the common set of constructs considered as core nurses competencies domestically and internationally. In this study, the final scale generated a total of five subscales: human understanding and communication skills, professional attitudes, critical thinking and evaluation; general clinical performance, and specific clinical performance. Thus, our set of subscales reflect the nursing competencies commonly measured in other countries and those that the Korean Accreditation Board of Nursing regard as essential (application of nursing knowledge, communication and collaborative skills, critical thinking, awareness of legal and ethical responsibilities, leadership, research skills, and adapting to global public health policy changes).

\section{Psychometric evaluation of the KNCCS}

In this study, we computed internal consistency (measured as the Cronbach's alpha coefficient) as our indicator of the equivalence reliability and we computed 
the test-retest reliability as our indicator of stability and reliability. Our findings showed high internal consistency and high stability, demonstrating the reliability of KNCCS. However, a few limitations to our performance evaluation instrument were found through content validating testing. We found that there were seven items that failed to reach an I-CVI of 0.7, covering important areas of nursing competency such as complementary and alternative therapy, critical care, supervision of nursing students, genetic nursing, and tailored nursing. Additionally, the explanatory factor analysis showed factor loading of less than 0.3 of item was one item $\# 29$ which was about the importance of spiritual care in nursing.

A core competency scale must represent essential competencies not only dealt in nursing education but also those that reflect the future. This is because nurses face challenges adapting to and keeping abreast of both societal and healthcare changes [20]. Nursing education must be constantly reviewed and developed to remain relevant so that nurses are prepared to the effects of globalization, changing patient characteristics, technological developments, progression of healthcare, and developments in policies and in the economy. Specifically, Hegarty et al. proposed that nursing education should address areas of transcultural nursing, patient-orientated care, chronic disease self-management, evidencebased nursing, leadership development, ethical and legal issues pertaining to patient healthcare, and international nursing standards [20]. Accordingly, as the instrument measuring the readiness of nurses to meet these challenges, the KNCCS should cover areas of multi- and trans-cultural society, complexities in healthcare, and technological advancement in a manner appropriate to the Korean context and should be continually reviewed and refined to reflect the changing healthcare environment.

\section{Conclusion}

We developed and validated a 70-item scale that quantifies core competences of graduating baccalaureate nurses in Korea. Each item was rated on a 5-point Likert scale. The strengths of the KNCCS are its conformity to the standards and criteria for the accreditation of baccalaureate nursing education programs proposed by the Korean Accreditation Board of Nursing; its contemporary and perspective content; and its congruence with the core competencies valued in other countries. We provide evidence of content validity of the scale that is based on the evaluation of seven content experts. We validated the scale by measuring its reliability and validity after pilot testing the scale on 528 novice nurses recently employed in nine major hospitals in Korea. Parameters of reliability and validity we used were internal consistency, test-retest reliability, and content validity. However, future studies assessing construct validity and criterion validity of the scale are still required. And the need to continually review and refine the scale must not be overlooked if it is to be an accurate measure of the effectiveness of baccalaureate nursing education programs in a constantly changing environment. 


\section{References}

[1] Ko, Y.K., Lee, T.W. and Lim, J.Y. (2007) Development of a Performance Measurement Scale for Hospital Nurses. Journal of Korean Academy of Nursing, 37, 286294. https://doi.org/10.4040/jkan.2007.37.3.286

[2] Lee, E.M. (2008) Development of Nursing Performance Appraisal Instrument [Dissertation]. Master Thesis, the Graduate School, Department of Nursing, Kyung Hee University, Seoul.

[3] Campbell, B. and Mackay, G. (2001) Continuing Competence: An Ontario Nursing Regulatory Program That Supports Nurses and Employers. Nursing Administration Quarterly, 25, 22-30. https://doi.org/10.1097/00006216-200101000-00006

[4] American Association of Colleges of Nursing (2009) The Essentials of Baccalaureate Education for Professional Nursing Practice. American Association of Colleges of Nursing Website. http://www.aacn.nche.edu/education/pdf/baccessentials08.pdf.

[5] Hsu, L.L. and Hsieh, S.I. (2009) Testing of a Measurement Model for Baccalaureate Nursing Students' Self-Evaluation of Core Competencies. Journal of Advanced Nursing, 65, 2454-2463. https://doi.org/10.1111/j.1365-2648.2009.05124.x

[6] Ahn, Y.H., Park, K.S., Yang, S.O., Shin, K.R. and Kim, M.J. (2005) Development of Standards and Criteria for Accreditation of Baccalaureate Nursing Education Program. Journal of Educational Evaluation for Health Professions, 2, 87-103. https://doi.org/10.3352/jeehp.2005.2.1.87

[7] Kim, M. (2006) Development of Objectives in Nursing Clinical Education Based on the Nursing Core Competencies. Journal of Korean Academy of Nursing, 36, 389402. https://doi.org/10.4040/jkan.2006.36.2.389

[8] Sung, M.-H. and Eum, O.B. (2009) Relationships between Critical Thinking Disposition, Professional Nursing Competence and Job Satisfaction in Clinical Nurses. Journal of Korean Academy of Nursing Administration, 15, 26-36.

[9] Kang, K.-S., Kim, C.-J., Lee, W.-H., Oh, E.-G. and Park, H.-O. (2004) A Study for the Evaluation of Students on a Practical Performance of the Home Health Care. The Journal of Korean Academic Society of Home Care Nursing, 11, 44-56.

[10] Lee, W.H., Kim, C.J., Yoo, J.S., Hur, H.K., Kim, K.S. and Lim, S.M. (1990) Development of a Clinical Competency Measurement Tool for Student. Journal of Nursing Science, 13, 17-29.

[11] Choi, E. (2009) A Study on the Relationship between Career Identity and Clinical Competency in Nursing Students. Journal of Korean Academic Society of Nursing Education, 15, 15-21. https://doi.org/10.5977/JKASNE.2009.15.1.015

[12] Polit, D.F. and Beck, C.T. (2006) The Content Validity Index: Are You Sure You Know What's Being Reported? Critique and Recommendations. Research in Nursing \& Health, 29, 489-497. https://doi.org/10.1002/nur.20147

[13] Lynn, M. (1986) Determination and Quantification of Content Validity Index. Nursing Research, 35, 382-386. https://doi.org/10.1097/00006199-198611000-00017

[14] Axley, L. (2008) Competency: A Concept Analysis. Nursing Forum, 43, 214-222. https://doi.org/10.1111/j.1744-6198.2008.00115.x

[15] Schwirian, P.M. (1978) Evaluating the Performance of Nurses: A Multidimensional Approach. Nursing Research, 27, 347-350. https://doi.org/10.1097/00006199-197811000-00004

[16] Benner, P. (1982) From Novice to Expert. American Journal of Nursing, 82, 402407. https://doi.org/10.1097/00000446-198282030-00004

[17] Meretoja, R., Isoaho, H. and Leino-Kilpi, H. (2004) Nurse Competence Scale: Development and Psychometric Testing. Journal of Advanced Nursing, 47, 124-133. 
https://doi.org/10.1111/j.1365-2648.2004.03071.x

[18] Cowin, L.S., Hengstberger-Sims, C., Eagar, S.C., Gregory, L., Andrew, S. and Rolley, J. (2008) Competency Measurements: Testing Convergent Validity for Two Measures. Journal of Advanced Nursing, 64, 272-277.

https://doi.org/10.1111/j.1365-2648.2008.04774.x

[19] Liu, M., Yin, L., Ma, E., Lo, S. and Zeng, L. (2009) Competency Inventory for Registered Nurses in Macao: Instrument Validation. Journal of Advanced Nursing, 65, 893-900. https://doi.org/10.1111/j.1365-2648.2008.04936.x

[20] Hegarty, J., Walsh, E., Condon, C. and Sweeney, J. (2009) The Undergraduate Education of Nurses: Looking to the Future. International Journal of Nursing Education Scholarship, 6, 1-11. https://doi.org/10.2202/1548-923X.1684 
Appendix 1. Korean Nurses' Core Competency Scale (KNCCS).

\begin{tabular}{|c|c|c|}
\hline $\begin{array}{c}\text { Item } \\
\text { no. }\end{array}$ & Subscales and item titles & $\begin{array}{l}\text { Factor } \\
\text { loading }\end{array}$ \\
\hline \multicolumn{3}{|c|}{ Subscale 1-Human understanding and communication skills } \\
\hline 34 & Help patients to articulate thoughts and emotions about their health. & 0.66 \\
\hline 40 & $\begin{array}{l}\text { Verbally communicate issues, emotions, } \\
\text { and thoughts relating to the nursing practice. }\end{array}$ & 0.62 \\
\hline 50 & Recognize patients as spiritual beings requiring spiritual care. & 0.62 \\
\hline 39 & Exchange constructive feedback and criticism between colleagues. & 0.59 \\
\hline 37 & $\begin{array}{l}\text { Help families of patients to respect patient } \\
\text { autonomy through sufficient consultations. }\end{array}$ & 0.58 \\
\hline 48 & Recognize the support and the help that colleagues need. & 0.58 \\
\hline 36 & $\begin{array}{l}\text { Demonstrate therapeutic communication skills, such as sympathy, } \\
\text { listening skills, restating patients' accounts, and clarifying an issue. }\end{array}$ & 0.55 \\
\hline 41 & $\begin{array}{l}\text { Establish productive working relationships with colleagues } \\
\text { and within the healthcare institution. }\end{array}$ & 0.54 \\
\hline 49 & Explain coherently the physical, the mental, and the social needs of a patient. & 0.54 \\
\hline 38 & Support nursing students to reach the objectives of their clinical training. & 0.53 \\
\hline 51 & $\begin{array}{l}\text { Understand the different needs of patients from } \\
\text { culturally diverse backgrounds in a cross-cultural society. }\end{array}$ & 0.51 \\
\hline 47 & Recognize the values, the strengths, and the weaknesses of self. & 0.51 \\
\hline 45 & $\begin{array}{l}\text { Seek help to relevant persons for } \\
\text { nursing resources (including human resources). }\end{array}$ & 0.49 \\
\hline 52 & $\begin{array}{l}\text { Incorporate the needs of the individual into the } \\
\text { nursing plan or adapt it as necessary. }\end{array}$ & 0.49 \\
\hline 43 & $\begin{array}{l}\text { Assess the progress of nursing care or patient } \\
\text { education with relevant members of the healthcare team. }\end{array}$ & 0.43 \\
\hline 46 & $\begin{array}{l}\text { Document medical records to promote better } \\
\text { communication between team members. }\end{array}$ & 0.43 \\
\hline 54 & $\begin{array}{l}\text { Teach patients through appropriate educational mediums } \\
\text { or those preferred by the patient. }\end{array}$ & 0.42 \\
\hline 35 & $\begin{array}{l}\text { Communicate to patients the procedural aspects, contents, } \\
\text { and purposes of the medical service that they will receive. }\end{array}$ & 0.41 \\
\hline 53 & $\begin{array}{l}\text { Provide a differential approach to patient education } \\
\text { according to the developmental stage of the patient. }\end{array}$ & 0.40 \\
\hline 42 & Plan nursing interventions that reflect opinions of multidisciplinary teams. & 0.35 \\
\hline 44 & $\begin{array}{l}\text { Give a comprehensive report of the patient's condition } \\
\text { during ward rotations or during delegation or transfer of roles. }\end{array}$ & 0.35 \\
\hline \multicolumn{3}{|c|}{ Subscale 2-Professional attitudes } \\
\hline 59 & $\begin{array}{l}\text { Practice in accordance to the philosophy, the policies, } \\
\text { and the values of the healthcare institution. }\end{array}$ & 0.73 \\
\hline 60 & Adhere to the legal and ethical roles and responsibilities of a nurse. & 0.72 \\
\hline 64 & Display a positive attitude, take initiatives, and set an example to others. & 0.70 \\
\hline 58 & $\begin{array}{l}\text { Participate actively in educational and research activities } \\
\text { for personal and professional development. }\end{array}$ & 0.70 \\
\hline 61 & Assume responsibility and accountability for owns role in nursing care. & 0.70 \\
\hline
\end{tabular}




\section{Continued}

Participate in enhancing the nursing profession by becoming involved in nursing associations or council activities.

Have a clear professional identity as a nurse.

Identify hazards to patient safety and make the necessary quality improvements to prevent harm.

Use self-reflective practice to prevent exhaustion of personal mental and physical resources.

Delegate nursing responsibilities appropriately and accept accountability for the consequences.

Recognize the importance of quality improvement and perform actions relating to this.

Communicate opinions on health policy as a member of society and as an expert in the medical healthcare profession.

Understand and perform the needs of socially-disadvantaged and vulnerable groups as their advocates.

\section{Subscale 3-Critical thinking and evaluation}

Make nursing and intervention decisions based on knowledge acquired from nursing education programs.

Prioritize nursing interventions as relevant to the patient.

Practice evidence-based nursing care.

Identify and use resources required for nursing care.

Consider the specific situation of the patient when making decisions in nursing care.

Judge the relevance of the decisions or instructions of various multidisciplinary experts.

Predict potential clinical hazardous situations of a patient.

Make decisions in nursing care that takes into account ethical values.

Use findings of nursing research in nursing practice.

Assess changes in patients continuously.

Systematically evaluate results of nursing care and level of patient satisfaction.

Provide nursing care that integrates needs of patients and their families.

Undertake decisions about the most optimal care for patient in multiple perspectives.

\section{Subscale 4-General clinical performance}

Use mechanical devices required for nursing care.

Administer drugs safely and accurately.

Perform the basic nursing techniques in nursing practice.

Use information technology in nursing care.

Share appropriate knowledge of self-care and teach techniques relating to this to patients impending discharge.

Have knowledge of the pharmacological effects and of the potential adverse effects of a drug and monitor the outcome accordingly. 


\section{Continued}

\begin{tabular}{|c|c|c|}
\hline 13 & $\begin{array}{l}\text { Be knowledgeable enough to understand } \\
\text { the pathophysiological state of a patient. }\end{array}$ & 0.42 \\
\hline 33 & $\begin{array}{l}\text { Provide discharging patients with information to resources of } \\
\text { the local community and of community health centers. }\end{array}$ & 0.40 \\
\hline 30 & Adapt teaching to the needs of the patient and family. & 0.40 \\
\hline 14 & $\begin{array}{l}\text { Practice accurate nursing assessment such as nursing } \\
\text { history and physical examination through questioning. }\end{array}$ & 0.39 \\
\hline 16 & Practice following a plan of nursing care. & 0.37 \\
\hline 18 & Comply with nursing standards and protocols of the healthcare institution. & 0.34 \\
\hline \multicolumn{3}{|c|}{ Subscale 5-Specific clinical performance } \\
\hline 56 & $\begin{array}{l}\text { Plan a tailored nursing intervention that considers } \\
\text { the patient's genetic characteristics. }\end{array}$ & 0.61 \\
\hline 26 & Perform nursing care required by critically ill patients. & 0.59 \\
\hline 27 & $\begin{array}{l}\text { Practice physical nursing that includes symptom } \\
\text { management in patients approaching their end of life. }\end{array}$ & 0.58 \\
\hline 25 & $\begin{array}{l}\text { Take appropriate actions in emergency } \\
\text { situations as a member of the medical team. }\end{array}$ & 0.56 \\
\hline 55 & Understand the genetic properties of patients. & 0.56 \\
\hline 24 & $\begin{array}{l}\text { Understand and evaluate the basis of which patients } \\
\text { who are receiving complementary alternative medicine receives it. }\end{array}$ & 0.51 \\
\hline 67 & Have knowledge of and follow regulations pertaining to emergency situations. & 0.43 \\
\hline 28 & $\begin{array}{l}\text { Demonstrate end-of-life care and meet the } \\
\text { emotional needs of patients and their families. }\end{array}$ & 0.34 \\
\hline 29 & Use resources to address the spiritual needs of patients. & 0.08 \\
\hline
\end{tabular}

\section{Submit or recommend next manuscript to SCIRP and we will provide best service for you:}

Accepting pre-submission inquiries through Email, Facebook, LinkedIn, Twitter, etc. A wide selection of journals (inclusive of 9 subjects, more than 200 journals)

Providing 24-hour high-quality service

User-friendly online submission system

Fair and swift peer-review system

Efficient typesetting and proofreading procedure

Display of the result of downloads and visits, as well as the number of cited articles

Maximum dissemination of your research work

Submit your manuscript at: http://papersubmission.scirp.org/

Or contact ojn@scirp.org 